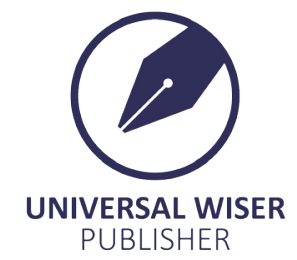

\title{
The Beveridge Curve in the Housing Market
}

\section{Gaetano Lisi}

Department of Economics and Law, University of Cassino and Southern Lazio, via S. Angelo, Campus Folcara, I-03043 Cassino, FR, Italy.

E-mail: gaetano.lisi@unicas.it

Abstract: As opposed to a recent criticism (according to which a model à la Pissarides inherently generates a downward sloping Beveridge curve), this short theoretical paper shows that a baseline search-and-matching model is able to take into account the main distinctive features of the housing market, thus generating an upward sloping Beveridge curve.

Keywords: Search-and-matching models, housing markets, Beveridge curve

\section{Introduction}

As in the labor market, the existence of search and matching frictions is one of the most important distinctive features of the housing market. This is the reason why the search and matching approach is largely used also in the housing market $^{[9]}$. Furthermore, housing markets exhibit some important stylised facts, namely, the positive correlation between selling prices and the number of houses for sale, and the trade-off between house prices and the time it takes to sell a house, the so-called time-on-the-market ${ }^{[1-11]}$.

According to Ortego-Marti and Gabrovski ${ }^{[12]}$, a baseline search-and-matching model à la Pissarides ${ }^{[13]}$ is unable to match the stylised facts of the housing market because "it inherently generates a downward sloping Beveridge Curve". In truth, while vacant units in housing markets naturally correspond to job vacancies in the labor market, the concept of unemployment is difficult to translate in the housing market ${ }^{[14]}$. It follows that some changes are needed in order to use the standard search-and-matching model à la Pissarides also in the housing market. For example, Ioannides and Zabel ${ }^{[14]}$ introduce a novel concept of "unemployment" in the housing market, thus allowing for the definition of Beveridge curve in housing markets.[Precisely, Ioannides and Zabel ${ }^{[14]}$ propose the concept of the "unfulfilled homeownership", namely the unfulfilled demand for owner occupied housing, as the counterpart of the unemployment rate (the unfilled demand for employment)]

In this preliminary theoretical paper, instead, we take another route and show that a much smaller change makes a baseline search and matching model capable of generating an upward sloping Beveridge Curve.

\section{The Model}

In a standard matching model à la Pissarides ${ }^{[13]}$, it is straightforward to find the trade-off between house prices and the time-on-the-market, since the time-on-the-market is merely the inverse function of the probability of filling a vacant house. Indeed, from the free-entry or zero profit condition, we find a positive relationship between house prices and time-on-themarket: higher prices imply more vacancies on the market and thus longer time to sell a house; while, from the generalised Nash bargaining solution, we find a negative relation between house prices and time-on-the-market: more vacancies on the market and thus longer time-on-the-market lead to lower prices. Hence, a baseline search and matching model is able to reproduce an important stylised fact of the housing market: the trade-off between house prices and the time-on-the-market.

According to Ortego-Marti and Gabrovski ${ }^{[12]}$, however, the related literature has not noted another important stylised fact: in the housing market, the counterpart of the empirical relation between job vacancies and unemployment, the socalled "Beveridge curve", is upward sloping (see Figure 1), namely buyers and vacant houses are positively correlated; whereas, any search model à la Pissarides "... inherently generates a downward sloping Beveridge Curve", specifically, therefore, a negative relation between vacancies and buyers (see Figure 1). 

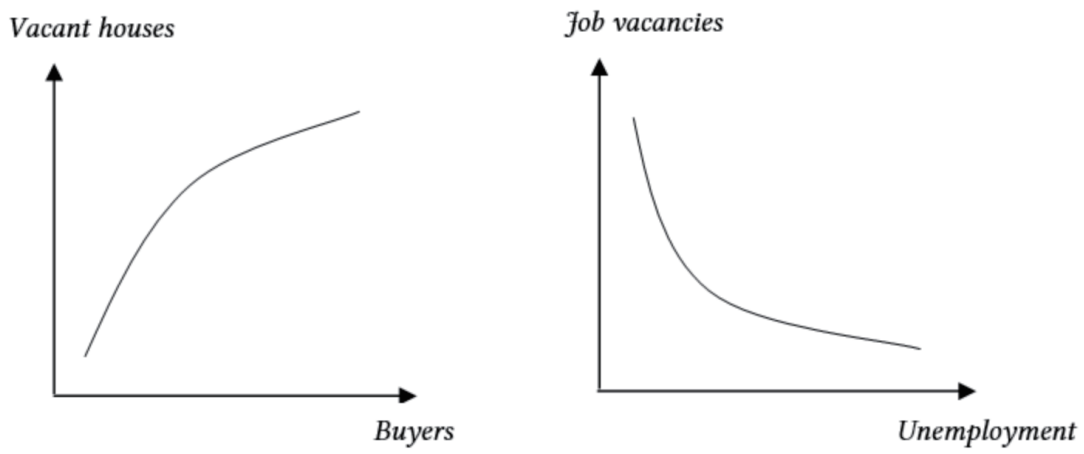

Figure 1. The Beveridge curve in the housing and labour markets

In the search model developed by Ortego-Marti and Gabrovski ${ }^{[12]}$, when sellers post more vacancies in the market, they make it easier for buyers to find a home. This raises the returns to search and incentivises buyers to enter the market, which increases the number of buyers. This entry mechanism leads to an upward sloping Beveridge Curve between vacancies and buyers.

However, they overlook an important feature of the housing market: buyers today are (potential) sellers tomorrow and vice versa ${ }^{[15-16]}$. Indeed, this is a realistic assumption that makes the standard model capable of generating an upward sloping Beveridge Curve.

Precisely, we assume that buyers $(b)$ already hold a house $(h=1)$, [Homelessness is in fact irrelevant in the housing market analysis, since buyers (the home seekers) are generally not homeless, they are tenants or have other housing arrangements (e.g. young people living with their parents).] and sellers $(s)$ hold $h>1$ houses of which $(h-1)$ are on the market. Hence, vacancies (v) are simply given by:

$$
v=\sum_{h=2}^{N}(h-1) \cdot S_{h}
$$

it follows that a (very intuitive) positive correlation among sellers, houses for sale and vacancies emerge from equation (1). More interestingly, if the number of buyers increases, ceteris paribus, more people can become sellers in the future, thus increasing houses for sale $(h)$. Indeed, this slight change enables a buyer to become a seller and vice versa, since a seller (with two houses) becomes a buyer after selling one house, while a buyer becomes a seller after buying another house. As a result, an upward sloping Beveridge Curve can be obtained in this model.

This key result can be shown in straightforward manner by introducing the value of the present discounted value (at the rate $(r)$ of a vacant house $(V)$ when a seller has only one house on the market (namely $h=2$ ), since only in this case a seller becomes a buyer after a trade:

$$
r \cdot V=-c+Q(v) \cdot[P-V+H]
$$

where $c$ is the cost of posting a vacancy (namely, the search cost of a seller), $Q$ is the probability of selling a vacant house (that, intuitively, depends negatively on the total number of vacant houses on the market), $P$ is the sale price and is the expected value of buyer' search. Concisely, when searching, the seller bears a cost flow $(-c)$ and if a trade is realised at the rate $Q$ (i.e., the match is successful), the seller gets the price, stops searching (thus giving up the value $V$ ) and becomes a buyers, thus getting the value $H$. It follows that the value $V$ also depends on the option to become a buyer in the future, viz.:

$$
V=\frac{-c+Q(v) \cdot[P+H]}{r+Q(v)}
$$

with $\frac{\partial V}{\partial H}>0$. Hence, the value of a vacant house depends positively on the value of buyer' search. It follows that a 
positive relation among sellers, vacancies and buyers emerge from the model.

However, the assumption that all buyers already own a house can be easily replaced. For example, we can assume that also exist first-time buyers, namely economic agents with $h=0$. At the time of purchase, however, they become buyers with $h=$ 1 , thus becoming sellers with an additional purchase. Hence, the core of the model does not change, since one match is still enough to have a "shift" in the position of economic agents (see Table 1).

Table 1. Buyers and sellers in the housing market

\begin{tabular}{ccc}
\hline If & an economic agent is a & that after a trade \\
\hline$h=0$ & (first-time) Buyer & remains a buyer \\
$h=1$ & Buyer & becomes a seller \\
$h=2$ & Seller & becomes a buyer \\
$h>2$ & Seller & remains a seller \\
\hline
\end{tabular}

For the sake of simplicity, we consider a very stylised price equation:

$$
P=\beta(v) \cdot x
$$

where $x$ is the bid price and $\beta(v)>0$ is the bargaining power of seller that depends negatively on vacancies. Indeed, the selling price depends negatively on vacancies due to the well-known congestion externality effect on the vacancies side ${ }^{[13]}$. Precisely, $\frac{\partial P}{\partial v}<0$ and $\frac{\partial^{2} P}{\partial V^{2}}>0$. From equation (2), instead, the free-entry condition (usually used in search-and-matching models) gives a positive relation between vacancies and house price, since $Q$ is decreasing in $v$ :

$$
V=0 \stackrel{\text { yields }}{\longrightarrow}[P+H]=\frac{c}{Q(v)}
$$

The system of equations (4) and (5), therefore, allows to get the equilibrium values of $P$ and $v$. Furthermore, it is possible to find the optimal number of houses per capita $\left(h=h^{*}\right)$ by maximising the expected overall profit, namely the profit arising from the sale of vacant houses on the market, viz.:

$$
\max _{h}\{(h-1) \cdot P[v(h)]\}
$$

The optimization condition gives the following result:

$$
\begin{aligned}
& P[v(h)]+(h-1) \cdot \frac{\partial P[v(h)]}{\partial h}=0 \\
& \stackrel{\text { yields }}{\longrightarrow} h^{*}=\frac{P[v(h)]}{\left\{\frac{\partial P[v(h)]}{\partial h}\right\}}+1>1
\end{aligned}
$$

Eventually, by deriving equation (7) with respect to the selling price, this simple model is also able to explain another important stylised fact of housing markets, namely, the positive relation between selling prices and the number of houses for sale, viz.: 


$$
\frac{\partial h}{\partial P}=\frac{(-1) \cdot\left\{\frac{\partial P[v(h)]}{\partial h}\right\}-\{-P[v(h)]\} \cdot \frac{\partial^{2} P[v(h)]}{\partial h^{2}}}{\left\{\frac{\partial P[v(h)]}{\partial h}\right\}^{2}}>0
$$

since the selling price is decreasing at decreasing rate in vacancies and, thus, on houses for sale. Once obtained the optimal number of houses per capita, equation (1) gives the share of sellers and by assuming an exogenous population $\Phi$ in the housing market, i.e., $\Phi=s+b$, the model is closed.

Of course, the proposed model is highly stylised and we aim to extend it in a short time. Nevertheless, also in this simplified form, the model clearly shows that a standard search-and-matching model à la Pissarides can generate an upward sloping Beveridge Curve in the housing market. This because the key assumption of the model (namely, the possibility that a buyer can become a seller and vice versa) is simple to introduce into the theoretical model but at the same time it is empirically realistic.

\section{References}

1] Anglin, Paul M., Ronald Rutherford, Thomas M. The Trade-off Between the Selling Price of Residential Properties and Time-on-the-Market: The Impact of Price Setting. Journal of Real Estate Finance and Economics. 2003; 26(1): 95-111.

[2] Cheng, P., Z. Lin, Y. Liu. A Model of Time-on-Market and Real Estate Price under Sequential Search with Recall. Real Estate Economics. 2008; 36(4): 813-43.

[3] Fisher, Jeffrey, Dean Gatzlaff, David Geltner, Donald Haurin. Controlling for the Impact of Variable Liquidity in Commercial Real Estate Price Indices. Real Estate Economics. 2003; 31(2): 269-303.

[4] Leung, Charles Ka Yui, Garion C. K. Lau, Youngman Chun Fai Leong. Testing alternative theories of the property price-trading volume correlation. Journal of Real Estate Research. 2002; 23(3): 253-264.

[5] Leung, Charles Ka Yui, Youngman Chun Fai Leong, Ida Yin Sze Chan. Time-On-the-Market: Why Isn't Price Enough? International Real Estate Review. 2002; 5(1): 91-115.

[6] Leung C.K.Y., Leong Y.C.F., Wong S.K. Housing Price Dispersion: An Empirical Investigation. Journal of Real Estate Finance and Economics. 2006; 32(3): 357-385.

[7] Merlo, Antonio, Francois Ortalo-Magne. Bargaining over Residential Real Estate: Evidence from England. Journal of Urban Economics. 2004; 56(2): 192-216.

[8] Seiler J. Michael, Sun Hua. Hyperbolic Discounting, Reference Dependence and its Implications for the Housing Market. Journal of Real Estate Research. 2013; 35(1): 1-23.

[9] Seiler J. Michael, Cheng P., Lin Z., Liu Y. The Benefit of Search in Housing Markets. Journal of Real Estate Research. 2015; 37(4): 597-621.

[10] Seiler J. Michael, He Xin, Zhenguo Lin, Yingchun Liu. Search Benefit in Housing Markets: An Inverted U-Shaped Price and TOM Relation. Real Estate Economics. 2017.

[11] Seiler J. Michael, Zhaohui Li, Hua Sun. Prospect Theory and Two-way Disposition Effect: Theory and Evidence from the Housing Market. Working paper. 2018.

[12] Ortego-Marti V., Gabrovski M. Housing Market Dynamics with Search Frictions. Working Papers. 2018.

[13] Pissarides C. A. Equilibrium Unemployment Theory. 2nd edition. Cambridge: MIT Press Books; 2002.

[14] Ioannides M. Y., Zabel J. E. Housing and Labor Market Vacancies and Beveridge Curves: Theoretical Framework and Illustrative Statistics. forthcoming in: Ioannides. Yannis M., Ed. Recent Developments in the Economics of Housing. Edward Elgar. 2018.

[15] Janssen J., Kruijt B., Needham B. The Honeycomb Cycle in Real Estate, Journal of Real Estate Research. 1994; 9(2): 237-252.

[16] Leung, Charles Ka Yui, Youngman Chun Fai Leong, Siu Kei Wong. Housing Price Dispersion: An Empirical Investigation. The Journal of Real Estate Finance and Economics. 2006; 32(3): 357-385. 